\title{
DAMAGE CLASSIFICATION TO HISTORICAL WOODEN STRUCTURES: A PRELIMINARY SURVEY AND RECOMMENDATION FOR DONG MINORITY DRUM TOWERS
}

\author{
Shiruo Wang ${ }^{1 *}$ \\ ${ }^{1}$ School of Architecture, Soochow University, 215000, Suzhou, Jiangsu, China \\ *Correspondence: srwang@suda.edu.cn
}

KEY WORDS: Dong minority, Drum Tower, damage classification, wooden structure, recommendation.

\begin{abstract}
:
Wood as a common construction material in historical buildings, material characteristics and environmental condition is always the main causes to degradation. Dong minority Drum Tower is one of the essential parts of Chinese wooden structural heritage. However, Drum Towers are, at present, in a poor state of conservation, especially suffering from fire risks, biological attacks, mechanical failures and bad interventions.

This paper aims to record the observed damage through a classification approach that poses negative impact on the aesthetics and stability of Drum Towers. Firstly, based on the definition and term in relevant standards, a clear and structured damage classification on historical wooden structures is concluded according to the different hazard grades and causes, which are alteration, defect, deterioration and mechanical failure. Secondly, the characteristics of each damage in Drum Towers are revealed through the field survey and classification. At last, the actual condition is presented through a case study of Zengying Drum Tower. Subsequently, a multi-risks prevention in the Drum Tower is discussed, recommendations are proposed with the purpose of controlling the most fatal risks, ranging from insects and fungi risks with operable acceptance by local people and authorities.
\end{abstract}

\section{INTRODUCTION}

In wood science, defect defines all types of defects in wood that negatively affect the quality and function of wood. The national standard " Defects in Log" GB/T115-2017 divides wood defects into six categories: knots, cracks, trunk defects, wood structural defects, fungal defects, and injuries(Standardization Administration of China, 2017), which summarizes the natural defects of wood as a biological material. However, for wooden historical buildings, the type of damage to wooden components is not only the natural defects caused by the wood itself, but also the decay, discoloration, mould, and insect attacks caused by biological factors such as fungi and pests, material degradation caused by other non-biological factors, as well as deformation, slope, and disconnection, caused by mechanical failures. Among the components of historic timber buildings, the national standard "Technical Standard for Maintenance and Strengthening of Historic Timber Building" GB50165-2020 cited the concept of "damage point", that is, a damage point should be a component, node or part of the bearing structure is in the status of being unable to bear properly, or on the verge of destruction(Ministry of Housing and Urban-Rural Development of the People's Republic of China, 2020). The "damage point" emphasizes on mechanical factors that could be cause structural damage, However, material decay is less mentioned since it is another essential factor to structural damage. If the damage classification of historical building wood components directly refer to the above standards, there will still be situations where the definition is not comprehensive or clear, which has resulted in obscure determination of damage types of wood components during visual survey and inappropriate interventions could be adopted. The Drum Tower is the most crucial timber building and the landmark that identifies Dong minority's harmonious relationship between nature and man-made structures. Dong people strongly identify themselves with the Drum Tower. However, the conservation condition is poor. The previous contribution highlighted, but little studies have discussed the current risks or the damage classification of wooden structures.

\section{CLASSIFICATION AND CHARACTERISTICS OF DAMAGE ON WOOD STRUCTURES}

Taking the Italian standards on wood works as an example, the clear and comprehensive classification of wood damage is referred, according to the different causes and hazard grades, the classification is divided into alteration, defect, deterioration and mechanical failures.

\subsection{Alteration}

The definition and term is referred to the standard, UNI 11130: 2004 - Cultural heritage Wooden artefacts - Terms and definitions concerning wood deterioration: Any kind of modification to wood (biological, mechanical, chemical) or to metallic materials occurring after installation. Alteration does not necessarily imply a worsening of the characteristics of the wood, but natural modifications caused by environment, like the sunlight, wind, etc. Therefore, for the circumstance of Drum Tower, the alterations can be divided into change in color, dust and smoke deposition.

2.1.1 Change in color: Many of the chemicals of timber elements have some color and also that can be easily oxidized and form a new chemical with a different color. Since timber elements are exposed to air and sunlight, the exposure can result in rapid oxidation. Natural change of components that define color and weathering are often present on entire external wood surface. 
2.1.2 Dust and smoke deposition: Due to the constant use of fire-place by Dong people, the exposed timber elements are gradually impacted by the smoke. Limited darkening takes place with a general unattractive appearance, usually due to the presence of superficial material.

\subsection{Defect}

Defect implies wood features which can negatively influence strength and stiffness, and/or the general structural behaviour (e.g. the efficiency of joints) of timber members. Defects include knot and splitting, etc. Generally, knot is one of the defects that could provoke dangerous conditions, like slope of grain. However, knot is not considered as one of the defects in Drum Tower because of two reasons: firstly, their presence, extent and distribution have not been accounted for in terms of influence on strength, for instance based on some sort of visual grading approach. Secondly, local carpenters prefer to use the green wood with small knots(Figure 1), from their perspective, the more knots the timber has, the stiffer and better structural behavior it has. Apparently, the conclusion from their years long experience is totally opposite to the knowledge of timber engineering, which the knots would weaken the structural properties of wood. It is considered the prevalence of compressive and shear stresses could even take advantage of knots depend on the type of stress conditions.

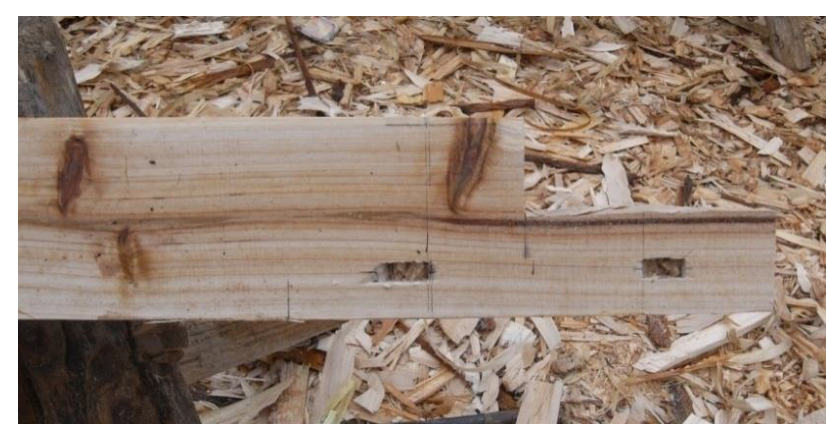

Figure 1. Green wood with knots used as wooden component

Shrinkage is a natural phenomenon in wood that can lead to splitting, it occurs because wood is a hygroscopic and anisotropic material, so the moisture content of wood changes in response to daily and seasonal changes in the relative humidity. When the air is humid, wood absorbs moisture and swells; when the air is dry, wood loses moisture and shrinks (Figure 2). Splitting can occur in longitudinal, radial, and tangential directions. They are very different in the three directions, and less important in the longitudinal direction. Splitting occur in Drum Towers distributed on the upper and lower surfaces of joint where connection between tie-beam and column is present, and expand along the depth direction(Figure 3). Splitting could cause a reduction of resistance and can pose serious risks to the whole structural frame.

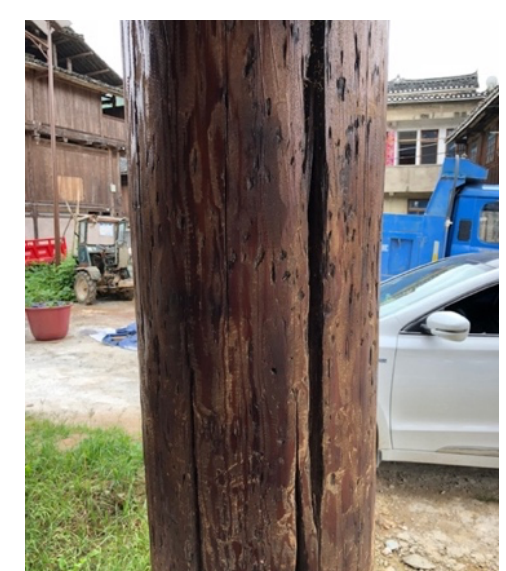

Figure 2. Splitting on column

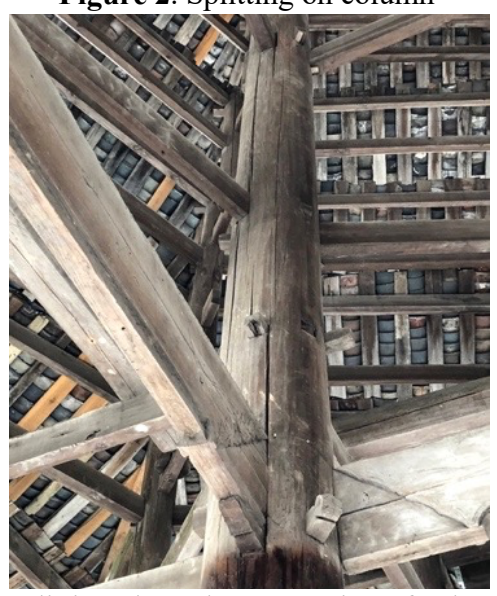

Figure 3. Splitting along the connection of column and tiebeams.

\subsection{Deterioration}

As the definition and term is referred to standard, UNI 11130: 2004 - Cultural heritage Wooden artefacts - Terms and definitions concerning wood deterioration, it means: Modification of wood, of different origins, which in any way worsens its characteristics (in particular, but not exclusively, the mechanical ones). In general, it can be caused by chemical, physical, mechanical, biotic agents and / or their combinations. Deterioration occurred in Drum Towers are not only caused by biotic agents, including insects, fungi, etc. but also physical or mechanical agents. Therefore, deterioration can be divided into insect attacks, rot (fungi attacks), lacuna (it could be caused by rot), detachment (usually caused by insect and fungi attacks) and discoloration. 
2.3.1 Insect attacks: The timber elements of Drum Towers are sometimes attacked by various types of wood-boring insects Many of the most destructive saprophyte insects are beetles (Coleoptera, such as Anobium punctatum and Hylotrupes bajulus). These beetles use the wood as food and abode, boring complicated cavities inside the timber, reducing the bearing strength(Figure 4). The second most destructive is the wood wasp (Imenopters), which causes less severe damage than the beetles. The wasps generally create a hole as a nest in the surface of the timber but do not live in the wood, the hole usually is not deep and could approximately contain one wasp (Figure 5). Termites (Isoptera Order) are extremely serious insect pests that affect timber, causing serious damage inside the wood that is barely visible from the outside(Figure 6). Wood decay caused by insects can lead to progressive loss of mass, resistance to load, and hardness, as well as weakened bearing sections.

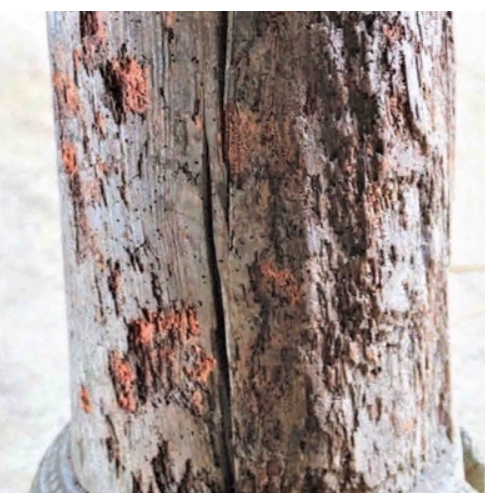

Figure 4. Column attacked by beetles

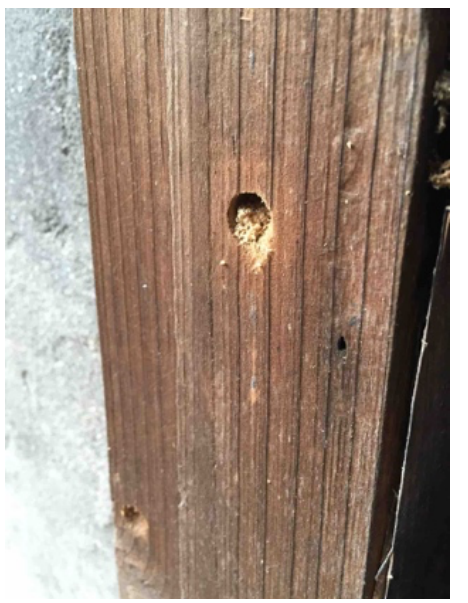

Figure 5. Timber attacked by wasps

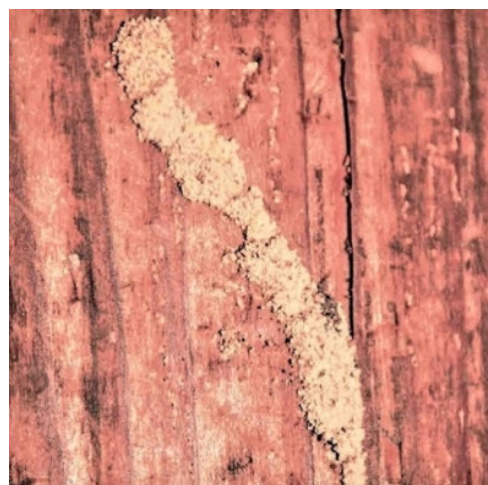

Figure 6. Timber attacked by termites
According to the survey investigation, the main insect pests are beetles, of which Anobium punctatum and Hylotrupes bajulus are common in the Dong area. Termites were rarely found in Dong Drum Towers during the investigation. However, termite prevention activities should also be conducted.

According to visual inspection and drilling testing, the insect attack grade of wood components is classified by five levels, " 0 " indicates no insect attacks, "1" indicates trace insect attacks, " 2 " indicates light insect attacks, " 3 " indicates minor insect attacks, "4" indicates severe insect attacks. The corresponding rot condition seen Table 1 .

\begin{tabular}{|c|c|c|}
\hline Grade & level & Rot condition \\
\hline $\begin{array}{l}\text { no insect } \\
\text { attacks }\end{array}$ & 0 & no wormholes from visual inspection, no \\
\hline trace & 1 & No more than 3 wormholes visible in the \\
\hline insect & & observation range, only short and \\
\hline attacks & & discontinuous cavities on the surface \\
\hline light & 2 & No more than 5 wormholes visible in the \\
\hline insect & & observation range, continuous cavities on \\
\hline $\begin{array}{l}\text { attacks } \\
\text { minor }\end{array}$ & & the surface, depth less than $2 \mathrm{~cm}$ \\
\hline minor & 3 & $5-10$ wormholes visible in the observation \\
\hline $\begin{array}{l}\text { insect } \\
\text { attacks }\end{array}$ & & range, continuous and intersect cavities \\
\hline $\begin{array}{l}\text { attacks } \\
\text { severe }\end{array}$ & & on the surface, depth more than $5 \mathrm{~cm}$ \\
\hline $\begin{array}{l}\text { severe } \\
\text { insect }\end{array}$ & 4 & Surface is densely covered with \\
\hline $\begin{array}{l}\text { insect } \\
\text { attacks }\end{array}$ & & wormholes, and the cavities inside the \\
\hline altacks & & $\begin{array}{l}\text { whole wood is honeycomb, and its } \\
\text { strength is completely lost. }\end{array}$ \\
\hline
\end{tabular}

Table 1. Insect attack grade of wood components.

2.3.2 Fungi attacks: Rot is usually caused by the fungi attacks. Most of the fungi have a fine network of "roots" (hyphae) that extensively extend within the substrate and grow together and result in a visible loss of mass, resistance to load, and hardness, as well as changes in color and appearance of the wood. Fungi are present only with humidity in wood of more than $18 \%$ $20 \%$. For Dong Drum Towers, there are two problems: the first main problem is absorption of water from the ground through capillary action (the conductive cells in wood), especially in the column without a platform that is directly in contact with the soil (Figure 7). Another problem is the risk of infiltration due to poor or absent tile maintenance(Figure 8).

According to visual inspection and drilling testing, the rot grade of wood components on enveloping layer is classified by five levels, " 0 " indicates no rot, " 1 " indicates trace rot, " 2 " indicates light rot, "3" indicates minor rot, " 4 " indicates severe rot. The corresponding rot condition seen Table 2 .

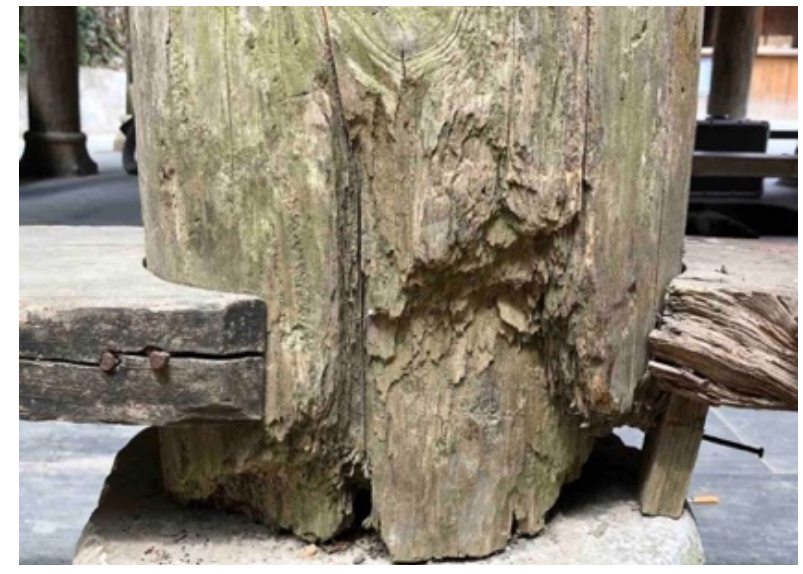


Figure 7. Rot in the bottom of column

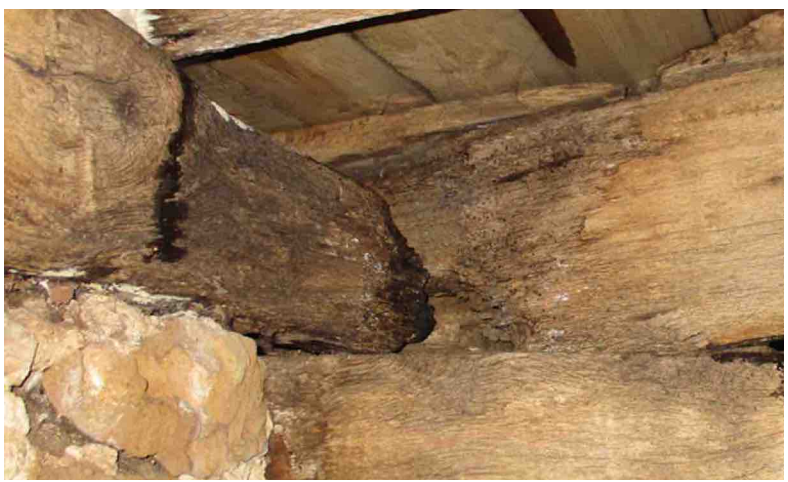

Figure 8. Rot on the top of column

\begin{tabular}{|c|c|c|}
\hline Grade & level & Rot condition \\
\hline no rot & 0 & no rot from visual inspection \\
\hline trace rot & 1 & $\begin{array}{l}\text { Trace rot on enveloping layer, depth less } \\
\text { than } 2 \mathrm{~mm} \text {, no impact on mechanical } \\
\text { properties }\end{array}$ \\
\hline light rot & 2 & $\begin{array}{l}\text { Light rot on enveloping layer, depth 2- } \\
5 \mathrm{~mm} \text {, less impact on mechanical } \\
\text { properties }\end{array}$ \\
\hline minor rot & 3 & $\begin{array}{c}\text { Obvious rot on enveloping layer, depth } 5 \text { - } \\
10 \text {, Obvious impact on mechanical } \\
\text { properties }\end{array}$ \\
\hline severe rot & 4 & $\begin{array}{l}\text { Severe rot, the rotten parts can be easily } \\
\text { broken and penetrated }\end{array}$ \\
\hline
\end{tabular}

Table 2. Rot grade of wood components on enveloping layer.

2.3.3 Lacuna, detachment and discoloration: Lacuna means a missing part that causes an empty space, obviously located in the place of some formerly existing part and it regards a portion of a wooden element; Detachment of a superficial layer of the timber element. Prelude to loss of the layer or limited decay of superficial layer on internal or external elements; Lots of decorated painting discolored from the wooden board below the roof. The discoloration negatively impact the appearance of Drum Tower and the value of decorative painting.

\subsection{Mechanical failure}

Definition and term are referred to standard, UNI 11138:2004- Cultural heritage, Wooden artefacts- Building load bearing structures - Criteria for the preliminary evaluation, the design- and the execution of works, the mechanical failure is: Changes of timber members or timber structures which appears as mechanical ruptures, caused by internal or external mechanical actions. However, for the circumstance of Drum Tower, the mechanical failure is not as serious as ruptures or cracks, but no more than disconnection. It is movement of element or of the structure, consisting of a mechanical disconnection due to internal or external actions.

The Drum Tower is a building with a wooden frame structure, and the load-bearing members are columns, main beams, and tiebeams. The roof is composed of a wooden base and construction materials such as mud, ash, and tiles. The wooden base contains rafters, slabs, and other components; the enclosed wooden board does not support the load, and is only used for maintenance and cold protection. Chuan-dou and Tai-liang are two structural typologies of the Drum Tower, the mechanical characteristics of two different types, the resulting damage to the components are different.
Tai-liang typology always applies a wooden frame with three or five main columns, the repeating and wooden frame extends horizontally to create an expanding interior space. This type of framework has excellent in-plane stability, but the number of outof-plane columns is relatively small, and usually consists of a small number of horizontal tie-beams. Therefore, this kind of typology would possibly cause a horizontal overall tilt (Figure 9).

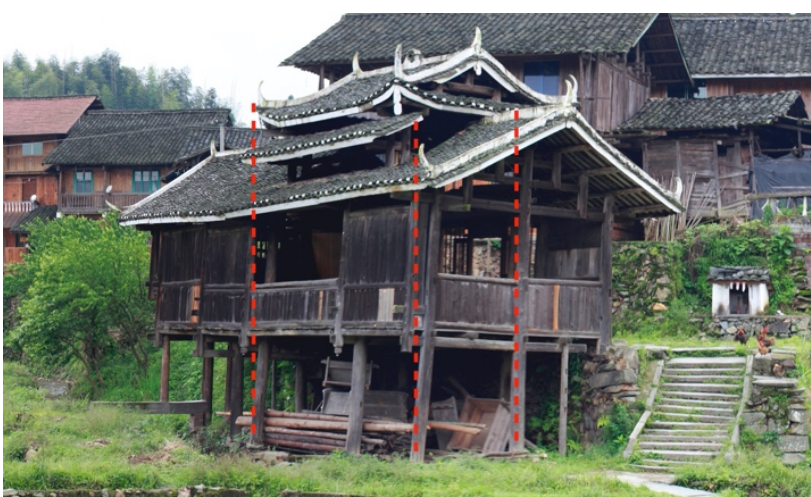

Figure 9. Overall tilt of a typical Tai-liang Drum Tower

Despite Chuan-dou Drum Tower has different roof morphology because of the structural configuration, they share a repeating wooden frame that consists of tie-beams and short columns. The structure has a strong stability. However, Chuan-dou Drum Tower usually has 5 to 9 stories, which suggest the load of upper frame is transferred to the main load-bearing elements of lower frame, that is the main columns and cross beams (Figure 10). Therefore, usually carpenters apply thicker main tie-beams and columns in Drum Tower.

It is found that there were a lot of splits are along the direction of wood fibre on the main columns and short columns of the Drum Tower. The splits distribute on the upper and lower surfaces of joint where connection between tie-beam and column, and expand along the depth direction. The splits s could be caused by the combination of shrinkage and the load of the upper frame.

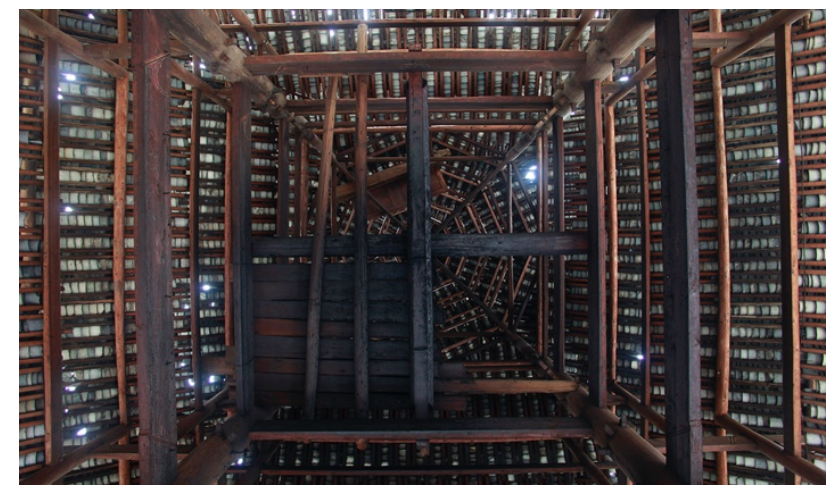

Figure 10. Timber frame of a typical Chuan-dou Drum Tower

Above all, regardless of Chuan-dou or Tai-liang typology, the main structural elements conform to the mechanical properties of the natural wood texture as well as the stress conditions. However, the stability of the structure is still inevitably confined to the different type of structural frame and mechanical anisotropy of wood. And the typical mechanical actions (spits, checks, disconnections, etc.) are mainly distributed at the joints of the tenon and mortises where the horizontal load-bearing members and the vertical load-bearing members are connected, and main columns and tie-beams. Therefore, any maintenance and reinforcement must first consider this problem. 


\section{A CASE STUDY: ZENGYING DRUM TOWER}

Zengying Drum Tower locates at Congjiang county, Guizhou. A typical Chuan-dou Drum Tower with 7 stories. It is protected at provincial level since 2015 (Figure 11). However, through field surveys, it is found that the wooden components of Zengying Drum Tower have been damaged in various grades and types, as well as additions and reconstructions. It is urgent to conduct damage investigation and analysis.

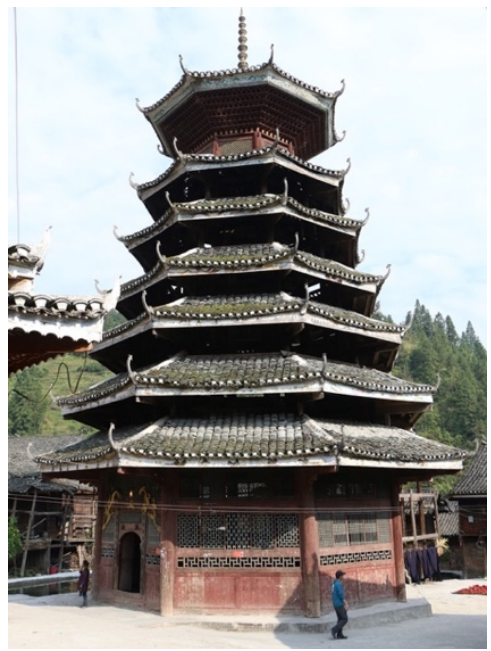

Figure 11. Zengying Drum Tower

\subsection{Identification and characteristics of wood species}

According to the dictation of local craftsmen and villagers, the wooden components of Zengying Drum Tower are made of local common materials, Baishan. Because local villagers usually describe tree species by common names, for example, in the southwest region of China, Huaqisong (Douglas fir) and Yangsong (poplar pine)Yangsong have two common names of "fir" and "pine"(Chen and Da, 2020). Therefore, its accurate botanical classification is required.

At present, the commonly used method for identifying tree species of wood components is based on the anatomical characteristics of wood. This identification method can generally identify the "genus" or "family". Follow the sampling method and slicing method in GB/T29894-2013 "General Methods of Wood Identification" (Standardization Administration of China, 2013). First, take on-site sampling of the wooden components of Zengying Drum Tower, and observe the macroscopic characteristics of the samples with visual inspection or a $10 \mathrm{x}$ magnifying glass. Secondly, by slicing the sample and preparing permanent sections, observe the microscopic characteristics of the sample from the transverse, tangential, and radial section (Figure 12). Finally, combining the macroscopic and microscopic characteristics, comparing the characteristics of wood specimens, it is comprehensively judged that the wood species used in the wood components of Zengying Gulou is China Fir (genus).
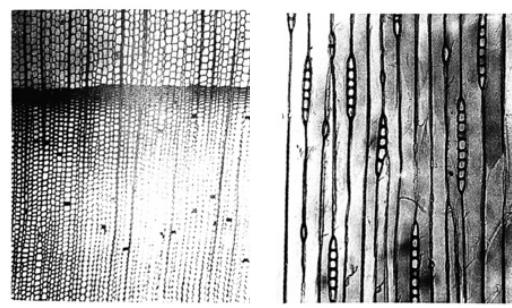

Transverse section radial section

Figure 12. Microscopic structure of wood sampling

With reference to the natural durability grades of common tree species in my country (including natural rot resistance and natural insect resistance) (Ma, Wang and $\mathrm{He}, 2013$ ), the natural rot resistance grade of Chinese fir is Class II "fair", and the quality loss rate is $11 \%-24 \%$. The natural insect resistance grade is "8: 3\%-10\% decay in the cross section" (Standardization Administration of China, 2009). The maximum compressive strength is $358 \mathrm{~kg} / \mathrm{cm}^{2}$, and the maximum static bending strength is $661 \mathrm{~kg} / \mathrm{cm}^{2}$. Therefore, Chinese fir has medium strength (Standardization Administration of China, 2009).

\subsection{Preliminary damage survey}

The problems in Zengying Drum Tower occurred in wooden elements (Table.3). Modifications are mapped in one of the representative sections (Figure 13), which reflect the distribution of the analysed features.

\begin{tabular}{|c|c|c|c|}
\hline Decay & Phenomenon & Position & Decay grade \\
\hline \multirow[b]{2}{*}{ Alteration } & Change in color & $\begin{array}{l}\text { Peripheral columns } \\
\text { and boards }\end{array}$ & - \\
\hline & $\begin{array}{l}\text { Smoke } \\
\text { deposition }\end{array}$ & $\begin{array}{l}\text { Inner columns and } \\
\text { beams upward the } \\
\text { fireplace }\end{array}$ & - \\
\hline Defect & Splitting & $\begin{array}{l}\text { connection between } \\
\text { the tie-beam and } \\
\text { column }\end{array}$ & - \\
\hline \multirow{5}{*}{ Deterioration } & Insect attack & $\begin{array}{l}\text { Short columns and } \\
\text { tie-beams }\end{array}$ & Light Insect 2 \\
\hline & Rot & $\begin{array}{l}\text { Bottom of the } \\
\text { peripheral column }\end{array}$ & Minor rot 3 \\
\hline & Lacuna & Short column & - \\
\hline & Detachment & $\begin{array}{l}\text { Surface of inner } \\
\text { column }\end{array}$ & Light rot 2 \\
\hline & Discoloration & $\begin{array}{l}\text { decorated painting } \\
\text { on wooden board } \\
\text { below the roof }\end{array}$ & - \\
\hline $\begin{array}{l}\text { Mechanical } \\
\text { failure }\end{array}$ & disconnection & $\begin{array}{l}\text { Connections } \\
\text { between column } \\
\text { and beams }\end{array}$ & - \\
\hline
\end{tabular}

Table 3. Damage classification in wood components of Zengying Drum Tower. 


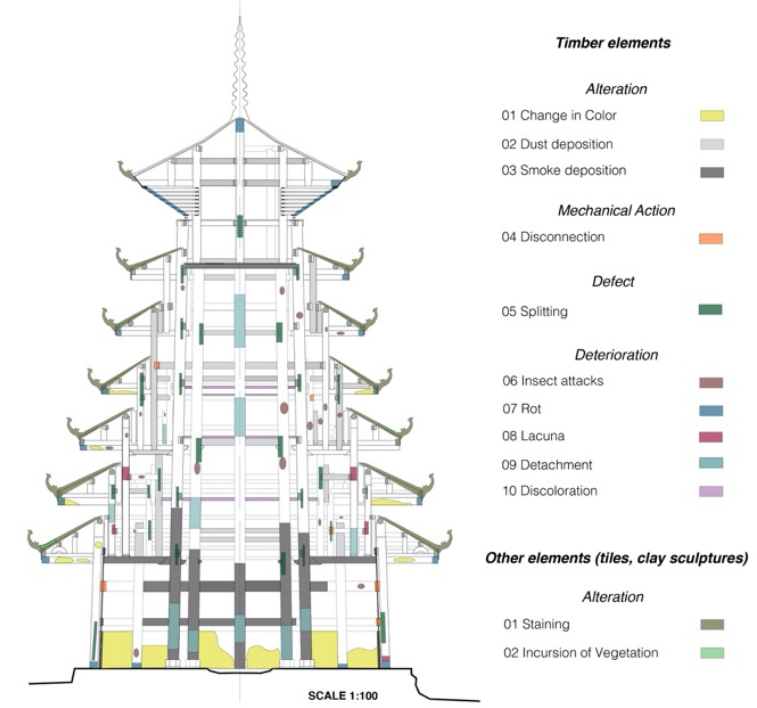

Figure 12. Distribution of damge in representative section of Zengying Drum Tower

Although Zengying Drum Tower has listed as a historical building protected at provincial level, the conservation and maintenance condition still remain negatively. Zengying Drum Tower encompasses alteration, defect, deterioration and mechanical failure, in which the problem of mechanical failure provoke less instability to wooden structure. Deterioration in Zengying Drum Tower address the primary risks that require proper intervention and maintenance. Insect attacks and rot has caused 2-3 decay grade to the wooden components. Therefore, a preliminary recommendation should be conducted foremost to the insect and fungi risks.

\subsection{Recommendations for controlling insect and fungi risks}

3.3.1 Control insect risks: For surveying wood condition, at least one local villager should be trained to use the tools, like an auger and a wooden mallet for checking if timber has been attacked by insects. A periodic survey of the timber condition and examination of early signs of insect attacks must be performed by well-trained villagers.

Firstly, to address the risk of beetle attacks: Apply transparent and uncolored preservative, which is brushed on to wooden elements for a better result; a double layer of preservatives should be applied using different techniques. Chemical treatment must be employed only if the attacks are active or it is determined that future attacks are probable after an in-deep survey.

Spray a preservative product within the building to create a fumigation fog. Fogs are particularly indicated where large or inaccessible places must be treated, such as the upper space in the Drum Tower, which is may be inaccessible if additional scaffolding or ladders are lacking. And smoke production in the Drum Tower have also contributed to prevent insects at some extend.

Secondly, the risk of wasp attacks must be addressed. Wasps create holes in the timber as a nest for laying eggs. Compared with other insect attacks, generally, the wasp attacks produce less damage. All the existing holes should be sealed with natural beeswax after monitoring the timber surface. If sealing is not effective against the wasp attacks, the applications for dealing with beetle attacks could be also applied.

Thirdly, the risk of termite attacks. The previous treatment with preservatives could also be effective against termites but may not be sufficient. The key method used to prevent termite attacks is to destroy the termites' community as much and as soon as possible. If the survey finds signs of termite attacks, electronic termite detector diagnostics could be employed by experts.

3.3.2 Control fungi risks: Rot is generally confined to areas where the moisture content in the timber has remained high. Therefore, identifying the origin of the dampness, stopping the entrance of moisture, and Maintaining Dryness are required.

For columns supported on a platform, the platform should be maintained in good condition avoiding the absorption of water from the soil. If the platform is in good conditions, regular checks of it are needed. If it is in poor conditions, with the column already decayed, then preservative treatment should be applied. For columns without a platform, adding a new platform under the column is not recommended. Preservative treatment should be applied on the foot of columns to avoid the absorption of water from the soil.

Due to the infiltration risk caused by rain, periodic maintenance of the roof tiles is greatly needed. Weeds or other plants should be entirely and regularly removed. Any applied chemical treatment should be safe for people using the Drum Tower as well as for the roof tiles or wooden components. The roof tiles should be cleaned regularly and checked for leaks. Any problems should be repaired from the roof to the column. If the cause of damage due to absorption and infiltration is addressed, no further interventions are required beyond maintaining the good condition and periodic surveys.

\section{CONCLUSIONS}

The damage classification to wooden components of historical buildings can be divided into four types: alteration, defect, deterioration and mechanical failures. Taking the Dong Drum Tower as an example, the alteration in enveloping layer of wooden components are mainly change in color, dust and smoke deposition, which provoke less risk to the structural stability. However, it is suffering a "chronic" risk, which requires proper and periodical maintenance, otherwise it will impact negatively on the aesthetic appearance, authenticity. The observed defects in Drum Tower are splitting, the impact on structural stability varies from its scale and position. For instance, two-way splitting along the diameter of the main bearing column occur on both sides could cause slope of grain if no intervention applied in time. Deterioration is one of the most risky damages for Drum Tower, which encompassing insect and fungi attacks. Especially the position occurred in 2-3 decay grade should be considered primarily. Mechanical failure in Drum Tower is mainly observed as disconnection and deformation.

Apparently, due to the frequent use of Drum Towers by local villagers, the risks to Drum Towers and to people who use them should be addressed. The general recommendations are aimed to control the problems during their initial stages. Hence, they were developed foremost for the local villagers and craftsmen, as well as experts to be simple, economic, and easy to implement with respect to the actual Drum Tower conditions. Although there are a lot of improvements which should be conducted in the future, this idea will hopefully serve as a protocol for Drum Tower preservation and maintenance in the Dong area, and be of benefit to similar wooden historical buildings.

\section{ACKNOWLEDGEMENTS}

The financial support of "Construction and Joint Research of China-Portugal Belt and Road Joint Laboratory on Cultural Heritage Conservation Science" (2021YFE0200100) and "China Postdoctoral Science Foundation" (2021M692352) are grateful acknowledged. Authors intends to acknowledge local authorities 
who offered a great support. Special acknowledgement to the skilled local carpenters and warm villagers.

\section{REFERENCES}

Chen L., Dai S., 2020: An Assumption on the Establishment of Historical Forest Reserves of the Wooden Built Heritage in China Based on Material Authenticity. Built Heritage, 134-141.

EN 844-8, 1997: Round and sawn timber-Terminology-Terms relating to features of round timber. European Committee for Standardization.

Jiang Z., Wood Properties of the Global Important Tree Species. Beijing: Science Press.

Ministry of Housing and Urban-Rural Development of the People's Republic of China. 2020: Technical standard for maintenance and strengthening of historic timber buildings: GB50165-2020. Beijing: Standards Press of China.

Ma X., Wang Y., He D., 2021: Damage and conservation of timber structure of historic building. Beijing: China Forestry Publishing House.

Standardization Administration of China. Defects in log: GB/T115-2017 [S].Beijing: Standards Press of China.

Standardization Administration of China. 2013: General methods of wood identification: GB/T29894-2013.Beijing: Standards Press of China.

Standardization Administration of China. 2009: General methods of wood identification: GB/T 13942, 1-2009. Durability of wood - Part 1: Method for laboratory test of natural decay resistance. Beijing: Standards Press of China.

Standardization Administration of China. 2009: General methods of wood identification: $G B / T$ 13942, 2-2009. Durability of wood - Part 2: Method for laboratory test of natural decay resistance. Beijing: Standards Press of China.

UNI 11130:2004-Cultural heritage, Wooden artefacts-Terms and definitions concerning wood deterioration. UNI Ente Nazionale Italiano di Unificazione.

UNI 11138:2004- Cultural heritage, Wooden artefacts- Building load bearing structures - Criteria for the preliminary evaluation, the design- and the execution of works. UNI Ente Nazionale Italiano di Unificazione.

Wang S., 2020: A Practical Guideline Initiative for Dong Minority Drum Towers under Biological Attacks. Architecture \& Culture, 219-221. 